\title{
Catalytic pyrolysis of straw biomasses (wheat, flax, oat and barley straw) and the comparison of their product yields
}

\author{
A. Aqsha, M. M. Tijani \& N. Mahinpey \\ Department of Chemical and Petroleum Engineering, \\ Schulich School of Engineering, The University of Calgary, Canada
}

\begin{abstract}
Biomass can be converted through a biochemical and also thermochemical process. Pyrolysis is considered one of the thermochemical processes that can be used to breakdown biomass into a liquid product called bio-oil. Pyrolysis of Canadian straw biomasses was studied using a thermogravimetric analyzer (TGA) and a bench-scale horizontal fixed bed reactor, to understand the devolatilization process and, to obtain information about their product yields. In this work, the results of experimental studies on the pyrolysis of several Canadian biomasses are described. The pyrolysis of straw biomass was performed in a fixed-bed reactor at temperatures of $500^{\circ} \mathrm{C}$, to study the influence of the feedstock on product distribution. The pyrolysis products were analyzed, and the effect of the catalyst on the product yield is also discussed. The yield of bio-oil and bio-char of the straw pyrolysis using zeolite catalysts was increased up to $46.44 \%$ and $38.77 \%$, respectively; while the bio-gas yield was decreased to as low as $13.65 \%$. The use of catalyst 2 (Zeolite YH2.2) had the most significant effect in increasing the yield of bio-oil about $2 \%$ and bio-char yield up to $8 \%$. The use of catalyst number 2 also showed the most significant effect during pyrolysis of flax straw by increasing the bio-oil yield up to $46.44 \%$. In the pyrolysis of oat straw, the use of catalyst consistently decreased the bio-gas yield; however, the bio-oil yield increased the most $(43.32 \%)$ with the use of catalyst 1 (Zeolite YS2.2). The use of catalyst 1 also increased the bio-oil yield during the pyrolysis of barley straw (43.03\%).

Keywords: biomass, biofuels, devolatilization process, kinetic of pyrolysis, proximate analysis, pyrolysis of biomass.
\end{abstract}




\section{Introduction}

Nowadays, biomass can be converted to various forms of energy through several different processes (chemical, biological, and thermochemical) as an alternative to fossil fuel such as gasoline and petrodiesel or into value added chemicals. Lignocellulosic straw biomass is considered one of the promising renewable feedstock for the production of chemicals and biofuels and they are widely available in prairie region of Canada. The use of biomass or waste biomass such as wheat straw, flax straw, barley straw, or sawdust for energy production will provides several advantages from environmental perspectives.

Biomass can be converted through chemical, biochemical and also thermochemical conversion. Pyrolysis is considered one of the thermochemical processes that can be used to breakdown some materials into a liquid product called bio-oil (Mahinpey et al. [1]). Although pyrolysis is an old technology, there has been a lot of progress in the past decade and is becoming more attractive than other thermochemical processes (Scott and Piskorz [2]; Mohan et al. [3]). During pyrolysis, the applied heat will decompose the materials into volatile compound (condensed and uncondensed material) that later will produce bio-char, bio-oil, and bio-gas.

Like wood, straws biomass (wheat, flax, barley, oat) are primarily composed of cellulose, lignin and hemicellulose (Bicho and Stumborg [4]). Each of straw biomass has different composition and suspected to have significant effects on the product yield and composition (Wang et al. [5]). Temperature of the reaction, heating rate, particle size, and residence time are parameters that significantly affect the properties of the product and its composition (Beis et al. [6]; Vamvuka [7]). For instance, Haykiri-Acma [8] suggested that increasing the heating rate to $50^{\circ} \mathrm{C} / \mathrm{min}$ led to higher conversion rates due to the better mass and heat transfer inside the reactor (Biagini et al. [9]). In addition, the temperature of $500^{\circ} \mathrm{C}$ should be used to maximize the liquid oil yield (Mani et al. [10]). If these parameters are not used, secondary reactions may occur, thus decreasing the oil yield, which leads to higher yield of gas and char (Hosoya et al. [11]).

In this work, the results of experimental studies on the pyrolysis of several Canadian biomasses were described. The pyrolysis of straw biomasses (barley, flax, oat and wheat straw) was performed in a fixed-bed reactor at temperatures of $500^{\circ} \mathrm{C}$ to study the influence of the feedstock on product distribution. The pyrolysis products were analyzed, and the effect of the catalyst on the product yield was also discussed. To evaluate the effects of the zeolite catalyst on the straws, three forms of the zeolite catalysts were used (silica based solution, $\mathrm{H}$ form of silica based solution, and silica sodium based solution). The results from the comparison of biomasses provide useful information about the suitability of biomass for particular end products such as bio-char, bio-oil, and bio-gas. 


\section{Experimental section}

\subsection{Materials}

The straw biomass samples (barley, flax, oat and wheat straw) used in this study were obtained from a farm in Saskatchewan, Canada. Straws biomasses were ground and sieved to obtain an average particle size less than $1 \mathrm{~mm}$. The chemical composition of the samples is given in Table 1 .

Table 1: Chemical composition of wheat, flax, oat and barley straw samples.

\begin{tabular}{|l|c|c|c|c|}
\hline & Wheat straw & Oat straw & Flax straw & Barley straw \\
\hline Cellulose & $34.2^{\mathrm{a}}$ & $37.6^{\mathrm{a}}$ & $53.0^{\mathrm{b}}$ & $33.8^{\mathrm{c}}$ \\
\hline Hemicellulose & $23.7^{\mathrm{a}}$ & $23.3^{\mathrm{a}}$ & $13.0^{\mathrm{b}}$ & $21.9^{\mathrm{c}}$ \\
\hline Lignin & $13.9^{\mathrm{a}}$ & $12.9^{\mathrm{a}}$ & $24.0^{\mathrm{b}}$ & $13.8^{\mathrm{c}}$ \\
\hline
\end{tabular}

${ }^{a}$ Adapa et al. [12]; ${ }^{b}$ Buranov and Mazza [13]; ${ }^{c}$ Mussatto and Teixeira [14].

\subsection{Proximate and ultimate analysis}

Proximate analysis of straw has been performed using a thermogravimetric analyzer (NETZSCH TG 209 F1 Libra). All experiments consist of three different steps: drying, devolatilization in a nitrogen inert atmosphere, and combustion with air (Figure 1). About $10 \mathrm{mg}$ of the sample with a particle size of $1 \mathrm{~mm}$ was used for this experiment. Initially, the biomass sample was kept at $25^{\circ} \mathrm{C}$ for $4 \mathrm{~min}$ in a nitrogen atmosphere. The moisture content was determined from the weight loss when the sample was heated at $85^{\circ} \mathrm{C} / \mathrm{min}$ up to $110^{\circ} \mathrm{C}$ and held constant for $5 \mathrm{~min}$. Devolatilization began once the temperature was at $110^{\circ} \mathrm{C}$, and the heating rate of $80^{\circ} \mathrm{C} / \mathrm{min}$ was maintained to $900^{\circ} \mathrm{C}$. The final temperature was held constant for $7 \mathrm{~min}$ in an air atmosphere to allow for complete combustion. The flow rate of the nitrogen and air was maintained at $45 \mathrm{~mL} / \mathrm{min}$. An ultimate analysis was performed using a $2400 \mathrm{CHNS} / \mathrm{O}$ analyzer (2400 elemental analyzer, Perkin-Elmer). The results of proximate and ultimate analyses of the biomasses are given in Table 2 .

Table 2: $\quad$ Proximate analyses of biomasses.

\begin{tabular}{|l|c|c|c|c|}
\hline & Wheat straw & Oat straw & Flax straw & Barley straw \\
\hline Moisture & 5.3 & 4.38 & 4.75 & 2.69 \\
\hline Volatile & 75.88 & 74.04 & 74.8 & 75.64 \\
\hline Fixed Carbon & 14.12 & 18.37 & 19.32 & 17.28 \\
\hline Ash & 4.69 & 3.21 & 1.12 & 4.38 \\
\hline
\end{tabular}




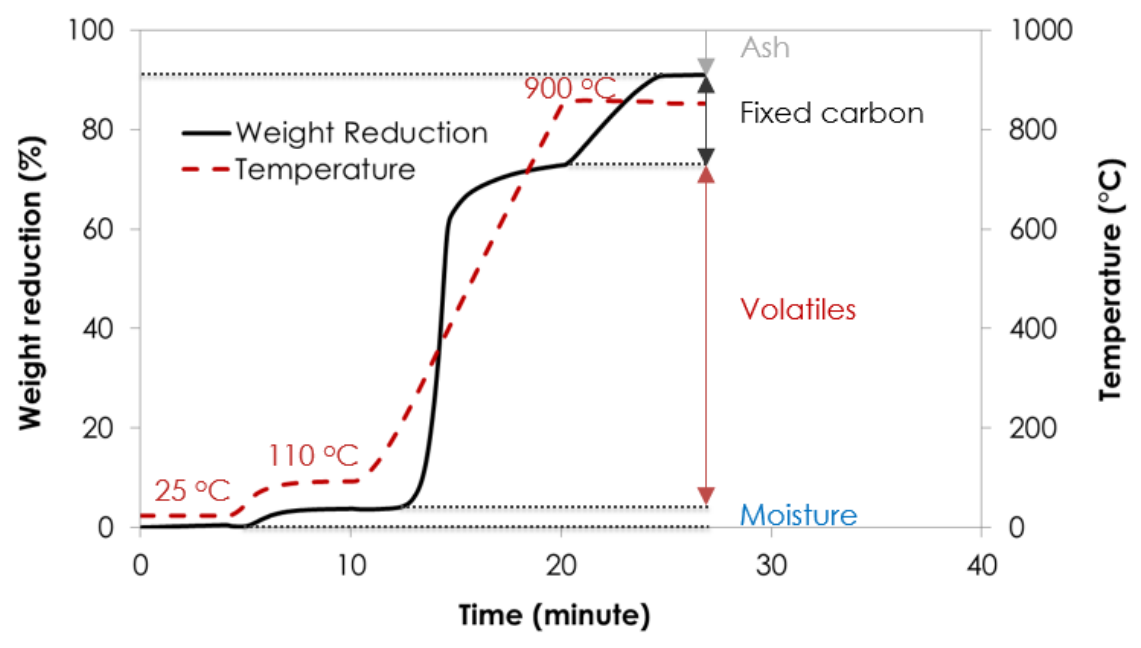

Figure 1: $\quad$ Typical TGA profile for proximate analysis using TGA.

Table 3: Elemental analysis of raw biomasses.

\begin{tabular}{|c|c|c|c|c|}
\hline Composition & Wheat straw & Oat straw & Flax straw & Barley straw \\
\hline $\mathrm{C}$ & 43.64 & 43.26 & 46.76 & 44.83 \\
\hline $\mathrm{H}$ & 5.82 & 6.12 & 6.34 & 6.25 \\
\hline $\mathrm{N}$ & 0.68 & 0.88 & 1.11 & 0.93 \\
\hline $\mathrm{S}$ & 1.08 & 1.14 & 1.14 & 1.18 \\
\hline
\end{tabular}

\subsection{Pyrolysis experiment}

Pyrolysis experiments were carried out using a thermogravimetric analyzer (NETZSCH TG 209 F1 Libra) and a batch-type horizontal reactor enclosed by a horizontal split tubular furnace. The reactor consists of a stainless-steel tube with a length of $535 \mathrm{~mm}$ and inside diameter of $22.5 \mathrm{~mm}$. Thermocouples were placed within the reactor system to measure the furnace temperature, pyrolysis reactor temperature, and outlet temperatures. Nitrogen was used as the inert gas with a constant flow rate of $50 \mathrm{~mL} / \mathrm{min}$ throughout the process. During the experiments, the sample was heated at a rate of $100^{\circ} \mathrm{C} / \mathrm{min}$ to a final temperature of $500^{\circ} \mathrm{C}$ at atmospheric pressure. At the end of the reactor, volatile products (gas and liquid) were separated using a separator that was submerged in a $0^{\circ} \mathrm{C}$ of liquid water-ice. The liquid products were collected and measured using a scale. The noncondensable gases were passed into an online gas chromatograph for gas analysis. For each experiment, $10 \mathrm{~g}$ of the straw biomass was loaded into the stainless-steel reactor. Each experiment was performed with the same amount of 
straw under temperature of $500^{\circ} \mathrm{C}$ for about 1 hour. The product yield was determined by weighing the char and liquid amount and subtracting them from the initial biomass weight. All of the experiments were performed twice. The error associated with the data was within $5 \%$.

\section{Results and discussion}

The result of proximate and ultimate analysis of all four biomass samples is presented on Table 2 and Table 3, respectively. The results demonstrate that the moisture content of the biomasses is in the range of 3-5\%, volatile content is about $74-76 \%$, fixed carbon is in the range of $14-19 \%$, and ash content is below $5 \%$. The volatile data from this analysis can be used to predict pyrolysis products. This volatile consist of condensable (bio-oil) and non-condensable material (bio-gas) that are produced during pyrolysis. The elemental analysis proved that the sulphur content of biomass is very small $(\sim 1 \%)$, while the oxygen content were about $45 \%$ (calculated by difference).

Table 4: Products comparison of pyrolysis of wheat, flax, oat and barley straw.

\begin{tabular}{|l|c|c|c|c|}
\hline \multicolumn{1}{|c|}{ Yield } & Wheat straw & Oat straw & Flax straw & Barley straw \\
\hline Bio-char & 36.21 & 32.65 & 32.14 & 33.51 \\
\hline Bio-oil & 40.48 & 40.04 & 40.18 & 35.83 \\
\hline Bio-Gas & 23.31 & 27.31 & 27.68 & 30.66 \\
\hline
\end{tabular}

A comparison can be made between the volatile content produced and the yield of bio-oil and bio-gas altogether from each sample (Table 4). It was shown that the yield of both products during pyrolysis was close to the volatile content data of each sample with discrepancy about 7-9\%. The total of bio-oil and biogas yield were always below the volatile content produced in proximate analysis. This discrepancy can be explained by the analysis of bio-char product from pyrolysis as shown on Table 5. The elemental analysis of bio-char produced during pyrolysis still contained about $3 \%$ of hydrogen and about as high as $26 \%$ oxygen. The availability of hydrogen, oxygen, and carbon in the char can be used to produce more volatiles (bio-oil and bio-gas) with the use of catalyst, faster heating rate, or perhaps different pyrolysis temperature.

A lower value of sulphur content on the bio-char (Table 5) compared to the value in the raw biomass sample (Table 3) suggested that half of the sulphur might be converted to $\mathrm{SO}_{2}$ by oxidation, $\mathrm{H}_{2} \mathrm{~S}$ by reduction, and COS. Shao et al. [15] concluded that $\mathrm{SO}_{2}, \mathrm{H}_{2} \mathrm{~S}$, and $\mathrm{COS}$ gases can be produced under pyrolysis condition $\left(200-500^{\circ} \mathrm{C}\right)$. 
Table 5: Elemental analysis of bio-char produced from each biomass samples.

\begin{tabular}{|c|c|c|c|c|}
\hline Composition & WS char & OS char & FS char & BS char \\
\hline $\mathrm{C}$ & 67.87 & 66.42 & 71.73 & 72.61 \\
\hline $\mathrm{H}$ & 2.97 & 2.34 & 2.8 & 3.09 \\
\hline $\mathrm{N}$ & 3.02 & 1.26 & 2.32 & 1.73 \\
\hline $\mathrm{S}$ & 0.55 & 0.49 & 0.61 & 0.62 \\
\hline
\end{tabular}

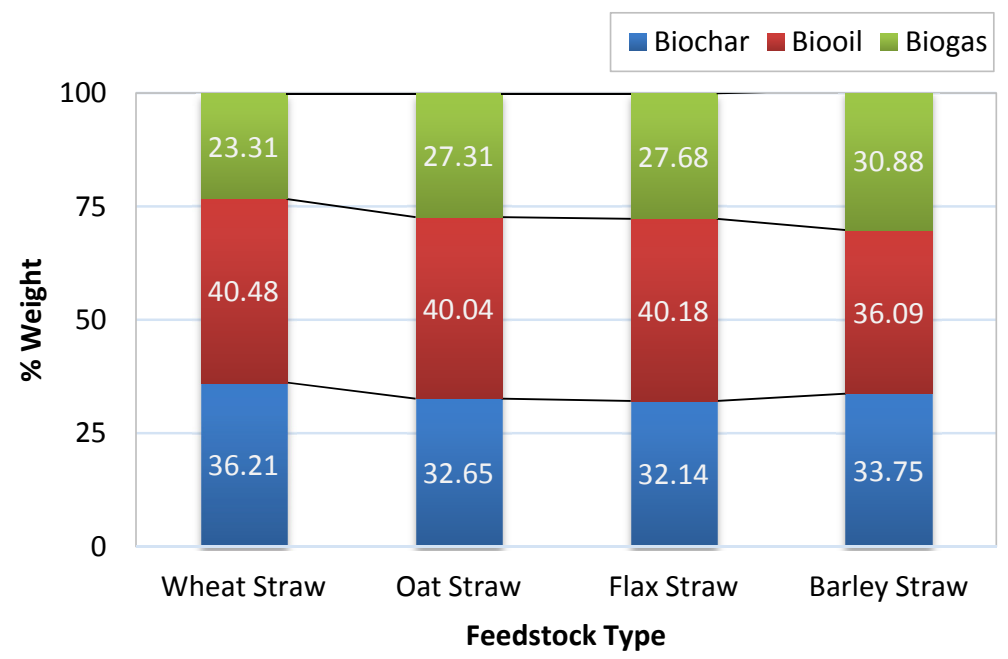

Figure 2: Product yields of biomasses pyrolysis.

The yield of pyrolysis products, such as liquid, gas, and char from all biomasses were presented in Figure 2. The bio-oil yield was maximized at $40.18 \%$ from wheat straw biomass, while the maximum gas yield of $30.88 \%$ was obtained from barley straw. In terms of bio-char product, the yield is in the range of $32.14 \%$ to $36.21 \%$. The difference between the product yields between biomasses may be influenced by the composition of the raw biomasses (Table 1); however, there is no clear trend between the structural composition of biomasses and the yield of the product. Nonetheless, the ash composition data from proximate analysis suggest that the higher the ash content of the biomasses the lesser bio-gas can be produced during pyrolysis.

Three different catalysts have been used in the experiment in order to see their effect on the product yield. As seen in Table 6 and Figure 3, the use of catalyst 2 (Zeolite YH2.2) had the most significant effect in increasing the yield of bio-oil about $2 \%$ and bio-char yield up to $8 \%$. Also, the use of catalyst number 2 confirmed the most significant effect during pyrolysis of flax straw by increasing 
Table 6: Product comparison of pyrolysis of wheat straw using catalyst.

\begin{tabular}{|l|c|c|c|c|}
\hline & Wheat straw & + Catalyst 1 & + Catalyst 2 & + Catalyst 3 \\
\hline Bio-char & 36.21 & 38.17 & 44.54 & 38.77 \\
\hline Bio-oil & 40.48 & 40.81 & 41.81 & 41.51 \\
\hline Bio-gas & 23.31 & 21.02 & 13.65 & 19.72 \\
\hline
\end{tabular}

the bio-oil yield up to $46.44 \%$. In the pyrolysis of oat straw, the use of catalyst decreased the bio-gas yield; however, the yield of bio-oil increased the most $(43.32 \%)$ with the use of catalyst 1 (Zeolite YS2.2). The use of catalyst 1 also increased the bio-oil yield during the pyrolysis of barley straw $(43.03 \%)$.

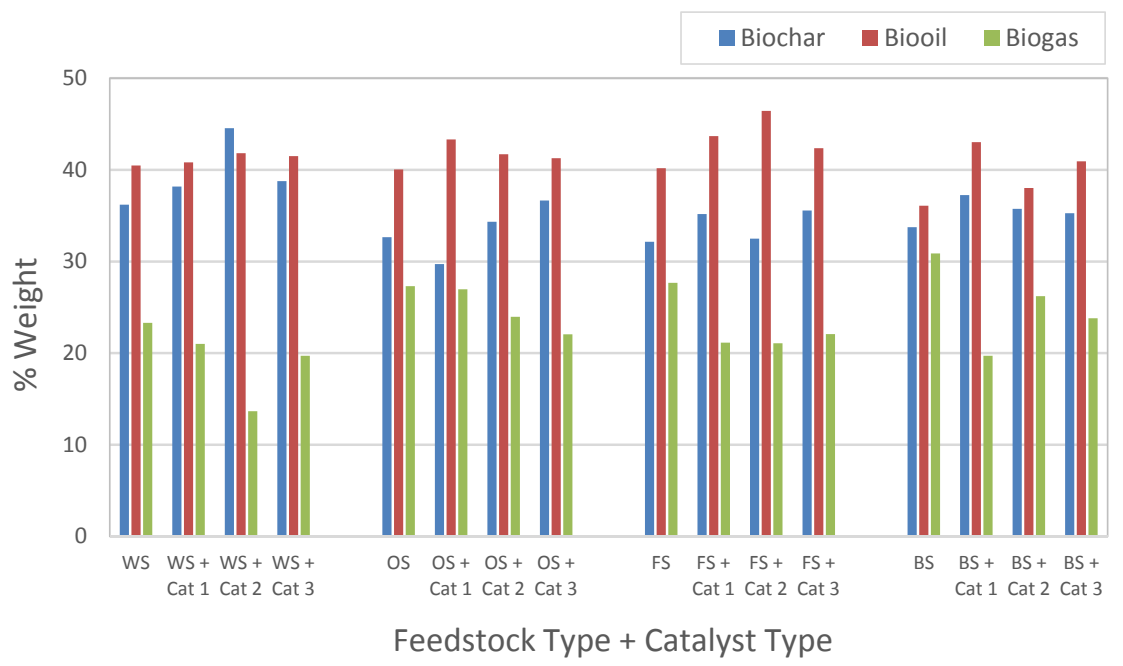

Figure 3: Comparison of the product yield among the biomasses.

\section{Conclusions}

The result of proximate analysis on raw biomasses can be used to predict the product yield produced during pyrolysis. The total yield of bio-oil and bio-gas were consistently lower than the volatile content produced in proximate analysis. The ash composition value from proximate analysis suggested that higher ash content suppressed the production of bio-gas. The pyrolysis of four different biomasses was performed with and without use of three different catalysts. It was observed that the bio-oil yield during the pyrolysis increased with the use of zeolite based catalyst. The use of Zeolite YH2.2 catalyst showed the most significant effect in increasing the bio-oil yield during the pyrolysis of wheat 
straw and flax straw, whereas the use of Zeolite YS2.2 showed the most significant effect during the pyrolysis of oat and barley straw.

\section{Acknowledgements}

The authors wish to acknowledge the financial support of the Natural Science and Engineering Research Council of Canada (NSERC) and the Ministry of Higher Education in the Kingdom of Saudi Arabia, and would like to thank Aurore Coussirat-Bourg for her contribution in the experimental part of this study.

\section{References}

[1] Mahinpey, N., Murugan, P., Mani, T. \& Raina, R., Analysis of bio-oil, biogas and bio-char from pressurized pyrolysis of wheat straw using a tubular reactor. Energy and Fuels, 23, pp. 2736-2742, 2009.

[2] Scott, D.S. \& Piskorz, J., The continuous flash pyrolysis of biomass. Canadian Journal of Chemical Engineering, 62, pp. 404-412, 1984.

[3] Mohan, D., Pittman, C.U. \& Steele, P.H., Pyrolysis of Wood/Biomass for Bio-Oil: A Critical Review. Energy Fuels, 20, pp. 848-889, 2006.

[4] Bicho, P.A. \& Stumborg, M.A., Wheat straw: a viable fibre source for Canada? Pulp \& Paper Canada, pp. 146-149, 1998.

[5] Wang, S., Guo, X., Wang, K. \& Luo, Z., Influence of the interaction of components on the pyrolysis behavior of biomass. Journal of Analytical and Applied Pyrolysis, 91 (1), pp. 183-189, 2011.

[6] Beis, S.H., Onay, Ö. \& Koçkar, Ö.M., Fixed-bed pyrolysis of safflower seed: influence of pyrolysis parameters on product yields and compositions. Renew. Energy, 26 (1), pp. 21-32, 2002.

[7] Vamvuka, D., Bio-oil, solid and gaseous biofuels from biomass pyrolysis processes - an overview. International Journal of Energy Research, 35 (10), pp. 835-862, 2011.

[8] Haykiri-Acma, H., Yaman, S. \& Kucukbayrak, S., Effect of heating rate on the pyrolysis yields of rapeseed. Renew. Energy, 31 (6), pp. 803-810, 2006.

[9] Biagini, E., Fantei, A. \& Tognotti, L., Effect of the heating rate on the devolatilization of biomass residues. Thermochimica Acta, 472 (1-2), pp. 55-63, 2008.

[10] Mani, T., Murugan, P., Abedi, J. \& Mahinpey, N., Pyrolysis of Wheat Straw in a Thermogravimetric Analyser: Effect of Particle Size and Heating Rate on Devolatilisation and Estimation of Global Kinetics. Chemical Engineering Research and Design, 478, pp. 1-7, 2010.

[11] Hosoya, T., Kawamoto, H. \& Saka, S., Pyrolysis behaviors of wood and its constituent polymers at gasification temperature. Journal of Analytical and Applied Pyrolysis, 78 (2), pp. 328-336, 2007. 
[12] Adapa, P., Tabil, L. \& Schoenau, G., Compaction characteristics of barley, canola, oat and wheat straw. Biosystems Engineering, 104, pp. 335-344, 2009.

[13] Buranov, A. U. \& Mazza, G., Lignin in straw of herbaceous crops. Industrial Crops and Products, 28, pp. 237-259, 2008.

[14] Mussatto, S. I. \& Teixeira, J.A., Lignocellulose as raw material in fermentation processes. Current Research, Technology and Education Topics in Applied Microbiology and Microbial Biotechnology, pp. 897907, 2010.

[15] Shao, D., Hutchinson, E.J., Heidbrink, J., Pan, W. \& Chou, C., Behaviour of sulphur during coal pyrolysis. Journal of Analytical and Applied Pyrolysis, 30, pp. 91-100, 1994. 